\title{
The Expression in Staphylococcus aureus of Cloned DNA Encoding Methicillin Resistance
}

\author{
By BARBARA INGLIS, P. R. MATTHEWS AND P. R. STEWART* \\ Department of Biochemistry, Faculty of Science, Australian National University, \\ Canberra ACT 2601, Australia
}

(Received 23 June 1987; revised 14 November 1987)

\begin{abstract}
A $4 \mathrm{~kb}$ fragment of chromosomal DNA was cloned from a clinical strain of methicillin-resistant Staphylococcus aureus. It comprises part of a section of the chromosome that was lost when the strain was cured of resistance to methicillin and to other antimicrobial agents. The fragment mediates an increased level of methicillin resistance when inserted into a shuttle vector and transformed back into the sensitive strain generated when the original DNA was deleted.
\end{abstract}

\section{INTRODUCTION}

The physiological expression of methicillin resistance in Staphylococcus aureus has been extensively studied since it was first observed more than 20 years ago, and the biochemical basis of the phenomenon has recently been linked to the production of an additional penicillinbinding protein (PBP) in resistant cells (Ubukata et al., 1985; Hartman \& Tomasz, 1986; Reynolds \& Fuller, 1986). The primary genetic determinant for methicillin resistance (mec) has been mapped on the $S$. aureus chromosome (Stahl \& Pattee, 1983), and may be located on transposable DNA (Stewart \& Rosenblum, 1980; Beck et al., 1986). Matsuhashi et al. (1986) have cloned DNA from the chromosome of a wild-type methicillin-resistant $S$. aureus (MRSA) strain which directs the synthesis in Escherichia coli of the new PBP, denoted PBP2a or PBP2', and have described the sequence of the gene and promoter for the new PBP (Song et al., 1987). A second chromosomal locus appears to be associated with the expression of mec (Berger-Bachi \& Kohler, 1983); this locus may be connected with resistance heterogeneity, a puzzling feature of many MRSA strains (Matthews \& Stewart, 1984; Hartman \& Tomasz, 1986).

In studies aimed at identifying DNA sequences which determine methicillin resistance, we reported the cloning of approximately $24 \mathrm{~kb}$ of chromosomal DNA from the Australian clinical MRSA strain ANS46. This $24 \mathrm{~kb}$ is part of a section of DNA deleted from the chromosome of ANS46 when the strain was cured of resistance to methicillin and to other antimicrobials, generating strain ANS62 (Matthews et al., 1987). We also demonstrated the association of a $3.5 \mathrm{~kb} \mathrm{BglII}$ fragment (MF5) of the cloned DNA with methicillin resistance in a methicillin resistant/sensitive strain pair constructed by transduction. Furthermore, MF5 showed strong homology to a mec-associated fragment of identical length and endonuclease map which had been cloned independently by Beck et al. (1986). MF5 was later shown to be present at one end of a larger section of chromosomal DNA which underwent amplification following step-selection of resistant strains to increased levels of resistance to methicillin (Matthews \& Stewart, 1988). The amplification was observed in two MRSA strains, ANS46 and an unrelated clinical strain of American origin, C5. The amplified sections of chromosomal DNA from the two strains appear to share endonuclease sites for only approximately $6.5 \mathrm{~kb}$.

MF5 comprises the right-most part of the cloned $24 \mathrm{~kb}$ of DNA from ANS46, and contains most of an approximately $1 \mathrm{~kb}$ direct repeat sequence which is present at three other locations in

\footnotetext{
Abbreviations: MRSA, methicillin-resistant Staphylococcus aureus; PBP, penicillin-binding protein; $\mathbf{M c}^{\mathrm{R}}$, methicillin resistance.
} 
this $24 \mathrm{~kb}$. The repeat shows strong homology to the putative insertion sequence IS 257 of $S$. aureus (Gillespie et al., 1987), and two of the three DNA sections flanked by the four copies of this IS257-like repeat show endonuclease map similarity to plasmid-located resistance determinants for mercury and tetracycline, both of which have been shown to occur also in the chromosome (Matthews et al., 1987; Witte et al., 1986; Gillespie et al., 1986). These two sections have been inserted separately into the shuttle vector pGC2, and shown to mediate resistance to mercury and to tetracycline when transformed into E. coli and into $S$. aureus (Skinner et al., 1988).

We report here the extension of the cloned region in ANS46 by the cloning of a $4 \mathrm{~kb}$ HindIII fragment (MA11), which overlaps MF5 by $1 \mathrm{~kb}$ and extends rightwards into the mec-associated, amplifiable region, to the point where the two amplified sections in ANS46 and C5 diverge. MA11 and MF5, subcloned into the shuttle vector pGC2, were used to transform ANS148, a chloramphenicol-sensitive derivative of ANS62. MA11 encodes methicillin resistance, whereas MF5 does not.

\section{METHODS}

Bacterial strains and plasmids. The $S$. aureus strains C5, ANS46 and ANS62 and the plasmid pMF5, a recombinant of pUC9 containing the $3.5 \mathrm{~kb} \mathrm{BglII}$ fragment MF5, have been described previously (Matthews et al., 1987). Construction of the shuttle vector pGC2 (a hybrid of the $S$. aureus chloramphenicol-resistance plasmid pC194 opened at its HindIII site and inserted into the PvuII site of the E. coli vector pGEM1) and subcloning into this vector were by standard methods (Maniatis et al., 1982). Strain ANS148 was obtained by curing ANS62 of the small (about $4 \mathrm{~kb}$ ) plasmid which encodes chloramphenicol resistance, by prolonged storage of the strain at room temperature. E. coli strain MC1061.1 was used as the transformation recipient for pGEM1 recombinant plasmids.

Assay of methicillin resistance. Minimal inhibitory concentrations (MIC) of methicillin were determined by dilution in tryptone soya (TS) broth (Oxoid), with an inoculum of $10^{5}$ cells $\mathrm{ml}^{-1}$. Growth was scored after 1 and $3 \mathrm{~d}$ incubation at $37^{\circ} \mathrm{C}$. Efficiency of plating (e.o.p.) of strains on varying concentrations of methicillin, at 30,37 and $42{ }^{\circ} \mathrm{C}$, was determined by plating suitably diluted TS broth cultures on TS agar containing a range of methicillin concentrations, and counting colonies after 1-4 d incubation. The e.o.p. is expressed as the surviving fraction of colony forming units, calculated by comparing counts with those on methicillin-free agar.

Disc-sensitivity testing, with discs containing $0.1 \mathrm{mg}$ methicillin, and calculation of the resistance parameter $\left(r_{\mathrm{d}}\right)$ from inhibition zone diameters, was done as described previously (Heneine \& Stewart, 1986).

Cloning of S. aureus chromosomal DNA. Procedures for the isolation of plasmid and chromosomal DNA, digestion with restriction endonucleases, recovery of selected fragments from agarose electrophoresis gels, and ligation of fragments into suitably cleaved and phosphatased vector DNA were described by Matthews et al. (1987). Probing of transformant colonies with labelled DNA was done by standard methods (Maniatis et al., 1982).

Protoplast transformation. Methods and media were mainly as described by Chang \& Cohen (1979) and Lindberg (1981) but with some modifications. Cells from $20 \mathrm{ml}$ overnight cultures were harvested by centrifugation at $16000 \mathrm{~g}$ for $10 \mathrm{~min}$ at $20^{\circ} \mathrm{C}$, and resuspended in $20 \mathrm{ml} \mathrm{SMMP} \mathrm{(Chang} \mathrm{\&} \mathrm{Cohen,} \mathrm{1979).} \mathrm{Lysostaphin}\left(30 \mu \mathrm{g} \mathrm{ml} \mathrm{m}^{-1}\right)$ and lysozyme $\left(2 \mathrm{mg} \mathrm{ml}^{-1}\right)$ were added and the cell suspension was incubated in a shaking water-bath at $37^{\circ} \mathrm{C}$ for $1.5 \mathrm{~h}$. Protoplasts were harvested from the lysate by centrifugation at $16000 \mathrm{~g}$ for $15 \mathrm{~min}$ at $20^{\circ} \mathrm{C}$, washed in $20 \mathrm{ml}$ SMMP, then resuspended in $1 \mathrm{ml} \mathrm{SMMP} \mathrm{by} \mathrm{gentle} \mathrm{vortexing.} \mathrm{This} \mathrm{method} \mathrm{gave} \mathrm{a} \mathrm{yield} \mathrm{of} \mathrm{protoplasts} \mathrm{from} \mathrm{whole}$ cells of $99 \%, 60-100 \%$ of which (the precise figure is not easily measured because of clumping of protoplasts) were viable as measured by growth on DM3 regeneration medium (Chang \& Cohen, 1979) containing $0 \cdot 1 \%$ glucose.

For each transformation, a $400 \mu \mathrm{l}$ sample of protoplasts was heat-shocked at $56^{\circ} \mathrm{C}$ for 2 min and cooled in a $20{ }^{\circ} \mathrm{C}$ water-bath; the DNA and $2 \mathrm{ml} 40 \%(\mathrm{w} / \mathrm{v})$ polyethylene glycol $(6000)$ were then added. After incubation at room temperature for $2 \mathrm{~min}, 7 \mathrm{ml} \mathrm{SMMP}$ was added. The protoplasts were harvested by centrifugation at $16000 \mathrm{~g}$ for $30 \mathrm{~min}$ at $20^{\circ} \mathrm{C}$, washed once in SMMP, gently resuspended in $1 \mathrm{ml} \mathrm{SMMP}$, and incubated at $37^{\circ} \mathrm{C}$ for 4-5 h to allow phenotypic expression of chloramphenicol resistance. Chloramphenicol $\left(1 \mu \mathrm{g} \mathrm{ml}^{-1}\right)$ was added for the final hour of this incubation.

Samples $(0.1 \mathrm{ml})$ of undiluted and a $10^{-1}$ dilution of the transformation mix were spread onto DM3 plates containing $5 \mu \mathrm{g}$ chloramphenicol ml $\mathrm{m}^{-1}$, and incubated at $37^{\circ} \mathrm{C}$ for $2-4 \mathrm{~d}$. Chloramphenicol-resistant colonies were replated onto TS agar containing $20 \mu \mathrm{g}$ chloramphenicol $\mathrm{ml}^{-1}$.

\section{RESULTS}

The fragments MF5 and MA11 are shown with the restriction endonuclease map of the relevant section of the ANS46 chromosome (Fig. 1). Fragment MA11 was isolated from a 


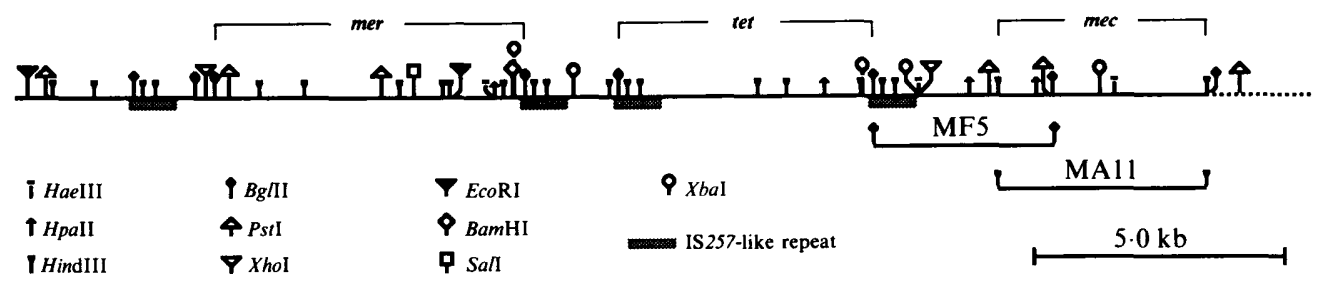

Fig. 1. Restriction endonuclease map of cloned segment of ANS46 chromosome. Sections expressing antimicrobial resistance are indicated above the map. Lines below map indicate fragments MF5 and MA11. HaeIII and HpaII sites are not mapped in the left-hand third of the segment.

Table 1. MIC and disc-sensitivity assays $\left(r_{d}\right)$ for methicillin

\begin{tabular}{|c|c|c|c|}
\hline & $\operatorname{MIC}(\mu \mathrm{g}$ & in $\mathrm{ml}^{-1}$ ) & \\
\hline & $24 \mathrm{~h}$ & $72 \mathrm{~h}$ & $(72 \mathrm{~h})$ \\
\hline ANS46 & 100 & 200 & 10 \\
\hline ANS 148 & 1.6 & $3 \cdot 1$ & 0.5 \\
\hline ANS148(GC2) & $1 \cdot 6$ & $3 \cdot 1$ & 0.5 \\
\hline ANS148(GC2-MF5) & $1 \cdot 6$ & $3 \cdot 1$ & 0.5 \\
\hline ANS148(GC2-MA11) & $12 \cdot 5$ & 100 & $2 \cdot 8$ \\
\hline
\end{tabular}

* Calculated from disc-sensitivity assays (Heneine \& Stewart, 1986).

library of ANS46 chromosomal HindIII fragments (size range $4 \cdot 0-4.5 \mathrm{~kb}$ ) cloned in pGEM1, which was screened by probing colonies with labelled pMF5 DNA. MA11 was characterized by isolation of plasmid DNA and its analysis by restriction endonuclease digestion and gel electrophoresis. Following the subcloning of MF5 and MA11 into pGC2, E. coli transformants carrying the recombinant plasmids were isolated and their plasmids characterized in the same way. The plasmids pGC2-MA11 and pGC2-MF5 were then propagated in E. coli and the plasmid DNA used for transformation of ANS148 protoplasts.

Plasmid DNA prepared from the resulting transformant clones of ANS148 was analysed by endonuclease digestion and gel electrophoresis. Those clones yielding plasmid DNA identical to the transforming DNA were assayed in broth for methicillin resistance, together with control and reference strains. Table 1 shows the mean results of six MIC assays; only the transformant strain carrying pGC2-MA11 demonstrated resistance to methicillin, although to a lesser extent than ANS46.

The strains ANS46, ANS148, ANS148(GC2) and ANS148(GC2-MA11) were then tested for the proportion of cells resistant to varying levels of methicillin (Fig. 2). ANS148(GC2-MA11) again was clearly resistant, though not to the same degree as ANS46. Assays of resistance distribution in populations of ANS46 and ANS148(GC2-MA11) were also done at high and low temperatures $\left(42^{\circ} \mathrm{C}\right.$ and $30^{\circ} \mathrm{C}$; Fig. 2); similar effects were seen for both strains. In discsensitivity testing, the lower expressed resistance of ANS148(GC2-MA11) compared with ANS46 was again evident (Table 1). In these experiments, heterogeneity of resistance for both strains was manifested by isolated colonies appearing within the zone of inhibition after incubation for $3-4 \mathrm{~d}$.

\section{DISCUSSION}

Although several laboratories, including our own, have reported the isolation of DNA associated with methicillin resistance (Beck et al., 1986; Matthews et al., 1987) or production of the new PBP2a (Matsuhashi et al., 1986), this cloned DNA has not so far been shown to transform sensitive $S$. aureus cells to methicillin resistance. We report here the construction and 

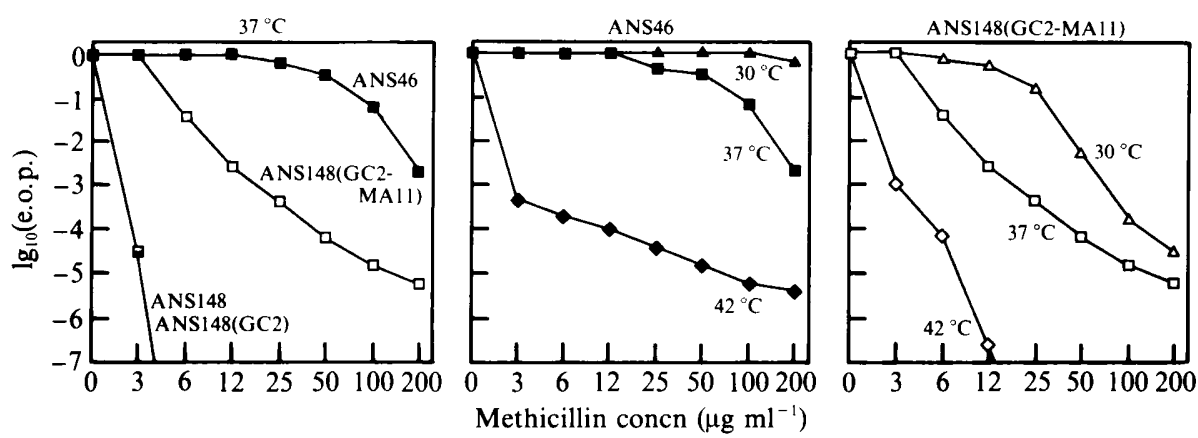

Fig. 2. Population analysis of strains. The e.o.p. of ANS148 and ANS148(GC2), ANS46 and ANS148(GC2-MA11) was determined at $37^{\circ} \mathrm{C}$, and of ANS46 and ANS148(GC2-MA11) at 30, 37 and $42{ }^{\circ} \mathrm{C}$.

use of the shuttle vector pGC2, which although not highly efficient in terms of utilization of transforming DNA, has been successful in unequivocally assigning resistance functions for mercuric ion and tetracycline to two cloned sections of chromosomal DNA (Skinner et al., 1988). In that study, the restrictionless strain SK982 was used as recipient in the transformation tests. pGC2-MF5 was stably transformed into this host, but did not mediate increased levels of methicillin resistance, and transformants of SK 982 carrying the pGC2-MA11 plasmid could not be obtained. However, by using ANS148, the chloramphenicol-sensitive derivative of ANS62, as transformation recipient, we appear to have overcome problems which may influence the stability of pGC2-MA11 after transformation, and/or be associated with the need for a second locus necessary for expression of methicillin resistance.

Transformation of ANS148 to chloramphenicol resistance with pGC2, pGC2-MF5 and pGC2-MA11 was achieved, and the presence of the intact plasmid confirmed in each case by isolation and analysis of plasmid DNA. Expression of methicillin resistance was obtained only in transformants carrying pGC2-MA11. Nevertheless, methicillin resistance expressed by the cloned sequence is not as great as that seen in the parental strain. This may suggest that other sequences concerned with chromosomal methicillin-resistance are present in the DNA lost from strain ANS46 in the construction of ANS148, but not in MA11. Alternatively, it may be that signals controlling expression, which function in $c i s$ in the parental strain, are less efficient in trans in the transformant.

Heterogeneity of expressed methicillin resistance is seen in ANS148(GC2-MA11), as well as in ANS46, to the extent that a minority, highly resistant population is seen at high methicillin concentrations in the population analyses (e.o.p. assays). Moreover, as is often the case for heterogeneously resistant MRSA, the proportion of highly resistant cells in cultures of ANS148(GC2-MA11) increases at $30^{\circ} \mathrm{C}$ and decreases at $42^{\circ} \mathrm{C}$.

In the MIC data of Table 1, ANS148(GC2-MA11) shows the largest increase from 24 to $72 \mathrm{~h}$; the $24 \mathrm{~h}$ MIC for ANS148(GC2-MA11) also showed a range of values $\left(3 \cdot 1-25 \mu \mathrm{g} \mathrm{ml}^{-1}\right)$ between experiments. This is probably due to heterogeneity and a slower growth rate for this strain in the presence of methicillin, common characteristics of MRSA strains (Dyke, 1969), and indicated for ANS148(GC2-MA11) by the slow and heterogeneous appearance of colonies during e.o.p. assays.

Since the completion of this study, Song et al. (1987) have reported the sequencing of $2.4 \mathrm{~kb}$ of the DNA found by Matsuhashi et al. (1986) to determine production of the mec-associated PBP2a, and describe an open reading-frame which encodes this protein. Comparing the restriction endonuclease sites present in that sequence with those in MA11, it is clear that a correspondence exists between the $2.4 \mathrm{~kb}$ described by Song et al. (1987) and a region of similar length within MAll, covering the Pst I, BglII, HpaII, XbaI and HaeIII sites shown in Fig. 1 . Within this region all sites marked in Fig. 1 agree with the sequence data of Song et al. (1987), insofar as the accuracy of agarose gel fragment sizing allows, with the exception of the $\mathrm{Xba}$ I site. 
At a position in the published sequence corresponding approximately with the position of this site, the hexanucleotide TCTAGG is found, which differs only in the final nucleotide from the $X b a \mathrm{I}$ recognition site. In addition, MA11 has been mapped for DraI, DdeI, and ClaI sites (data not shown), and the five sites so mapped match those present in the $2.4 \mathrm{~kb}$ published sequence. It thus appears that the $4 \mathrm{~kb}$ HindIII fragment of Song et al. (1987) and the $4 \mathrm{~kb}$ MA11 are essentially the same. Experiments to determine whether or not MA11 encodes PBP2a are currently in progress.

We thank Dr K. C. Reed for helpful discussions and advice. This work was supported by the National Health and Medical Research Council of Australia.

\section{REFERENCES}

BECK, W. D., Berger-BACHI, B. \& KAYSER, F. H. (1986). Additional DNA in methicillin-resistant Staphylococcus aureus and molecular cloning of mec-specific DNA. Journal of Bacteriology 165, 373-378.

Berger-BACHI, B. \& Kohler, M. L. (1983). A novel site on the chromosome of Staphylococcus aureus influencing the level of methicillin resistance: genetic mapping. FEMS Microbiology Letters 20, 305-309.

Chang, S. \& Cohen, S. N. (1979). High frequency transformation of Bacillis subtilis protoplasts by plasmid DNA. Molecular and General Genetics 168, 111-115.

DYKE, K. G. H. (1969). Penicillinase production and intrinsic resistance to penicillins in methicillinresistant cultures of Staphylococcus aureus. Journal of Medical Microbiology 2, 261-278.

Gillespie, M. T., May, J. W. \& Skurray, R. A. (1986). Detection of an integrated tetracycline resistance plasmid in the chromosome of methicillinresistant Staphylococcus aureus. Journal of General Microbiology 132, 1723-1728.

Gillespie, M. T., Lyon, B. R., LoO, L. S. L., Matthews, P. R., Stewart, P. R. \& Skurray, R. A. (1987). Homologous direct repeat sequences associated with mercury, methicillin, tetracycline and trimethoprim resistance determinants in Staphylococcus aureus. FEMS Microbiology Letters 43, 165-171.

Hartman, B. J. \& Tomasz, A. (1986). Expression of methicillin resistance in heterogeneous strains of Staphylococcus aureus. Antimicrobial Agents and Chemotherapy 29, 85-92.

Heneine, N. \& Stewart, P. R. (1986). Physiological determination of methicillin resistance in Staphylococcus aureus: comparison of clinical and genetically derived isolates. Journal of Antimicrobial Chemotherapy 17, 705-715.

LINDBERG, M. (1981). Genetic studies in Staphylococcus aureus using protoplasts; cell fusion and transformation. In Staphylococci and Staphylococcal Infections, Zbl. Bact. Suppl. 10, pp. 535-541. Edited by J. Jeljaszewicz. Stuttgart \& New York: Gustav Fischer Verlag.

Maniatis, T., Fritsch, E. F. \& SAmbrook, J. (1982). Molecular Cloning: a Laboratory Manual. Cold Spring Harbor, New York: Cold Spring Harbor Laboratory.

Matsuhashi, M., Song, M. D., Ishino, F., Wachi, M.,
DoI, M., Inoue, M., Ubukata, K., Yamashita, N. \& KONNO, M. (1986). Molecular cloning of the gene of a penicillin-binding protein supposed to cause high resistance to $\beta$-lactam antibiotics in Staphylococcus aureus. Journal of Bacteriology 167, 975-980.

MatThews, P. R. \& StEWART, P. R. (1984). Resistance heterogeneity in methicillin resistant Staphylococcus aureus. FEMS Microbiology Letters 22, 161-166.

Matthews, P. R. \& Stewart, P. R. (1988). Amplification of a section of chromosomal DNA in methicillin-resistant Staphylococcus aureus following growth in high concentrations of methicillin. Journal of General Microbiology 134, 1455-1464.

Matthews, P. R., ReED, K. C. \& SteWart, P. R. (1987). The cloning of chromosomal DNA associated with methicillin and other resistances in Staphylococcus aureus. Journal of General Microbiology 133, 1919-1929.

Reynolds, P. E. \& Fuller, C. (1986). Methicillinresistant strains of Staphylococcus aureus: presence of identical additional penicillin-binding protein in all strains examined. FEMS Microbiology Letters 33, 251-254.

Skinner, S., Inglis, B., Matthews, P. R. \& Stewart, P. R. (1988). Mercury and tetracycline resistance genes and flanking repeats associated with methicillin resistance on the chromosome of Staphylococcus aureus. Molecular Biology (in the Press).

SoNG, M. D., WACHI, M., DoI, M., Ishino, F. \& MatsuhashI, M. (1987). Evolution of an inducible penicillin-target protein in methicillin-resistant Staphylococcus aureus by gene fusion. FEBS Letters 221, 167-171.

Stahl, M. L. \& PatTeE, P. A. (1983). Confirmation of protoplast fusion-derived linkages in Staphylococcus aureus by transformation with protoplast DNA. Journal of Bacteriology 154, 406-412.

Stewart, G. C. \& Rosenblum, E. D. (1980). Genetic behaviour of the methicillin resistance determinant in Staphylococcus aureus. Journal of Bacteriology 144, 1200-1202.

Ubukata, K., Yamashita, N \& Konno, M. (1985). Occurrence of a $\beta$-lactam-inducible penicillin-binding protein in methicillin-resistant staphylococci. Antimicrobial Agents and Chemotherapy 27, 851-857.

Witte, W., Green, L., Misra, T. K. \& Silver, S. (1986). Resistance to mercury and to cadmium in chromosomally resistant Staphylococcus aureus. Antimicrobial Agents and Chemotherapy 29, 663-669. 